\title{
A Imagem como Elemento Mediador do Conhecimento: As Contribuições do Pibid nos Processos Formativos
}

\author{
Camila H. S. D Fonseca ${ }^{1}$, Síria L. Sampaio ${ }^{1}$, Ricardo J. R. Amorim ${ }^{1,2}$ \\ ${ }^{1}$ Mestrado em Educação e Diversidade - Universidade do Estado da Bahia (UNEB) \\ Campus IV - Jacobina - BA - Brasil \\ ${ }^{2}$ Colegiado de Computação \\ Faculdade de Ciências Aplicadas e Sociais de Petrolina (FACAPE) - Petrolina, PE - \\ Brasil \\ milaheveline@yahoo.com.br, \{siriasampaio, amorim.ricardo\}@gmail.com
}

\begin{abstract}
This article focuses on the use of image as a mediator element of learning. Its proposal to insert other critical understanding practices of visual artefacts in the school curriculum, based on the interventional actions of the Programa Institucional de Bolsa de Iniciação à Docência-PIBID. This proposal made it possible to take films to the school education practice, in order to promote the educational leisure and the approach of the community outside the school, providing opportunities for access to training and cultural properties offered by the cinema. In addition, the actions taken with use of cyberspace images favored the improvement of critical and reflective potential of students in front of the available visual collection on virtual or classroom environments, as well as gave opportunities to teachers the educational use of social networks.
\end{abstract}

Resumo. Este artigo versa acerca do uso da imagem como um elemento mediador das aprendizagens. Tem como proposta inserir outras práticas de compreensão crítica dos artefatos visuais no currículo escolar, tomando por base as ações interventivas do Programa Institucional de Bolsa de Iniciação à Docência - PIBID. Tal proposta possibilitou levar o cinema para a prática educativa escolar, com o intuito de promover o lazer educativo e a aproximação da comunidade externa à escola, oportunizando o acesso aos bens culturais e formativos oferecidos pelo cinema. Além disso, as ações implementadas com utilização das imagens do ciberespaço favoreceram o aprimoramento do potencial crítico-reflexivo dos discentes frente ao acervo visual veiculado em ambientes virtuais ou na sala de aula, bem como oportunizaram ao docente a utilização pedagógica das redes sociais.

\section{Introdução}

Este trabalho é fruto de ações interventivas do Programa Institucional de Bolsa de Iniciação à Docência - PIBID - que ocorreram nas cidades de Caém e Jacobina, na Bahia, realizadas por intermédio de dois subprojetos: (i) "Educação pela imagem: Formação cultural, leitura e escrita", que possibilitou a implementação da oficina "(Re)visando imagens nas redes sociais" em Caém e, (ii) "Cultura Visual e Aprendizagens: Leitura e Práticas Transversais", com o qual realizou-se a oficina "Cinema na Escola" em Jacobina, tendo como intuito promover lazer educativo aos estudantes e a comunidade externa. 
V Congresso Brasileiro de Informática na Educação (CBIE 2016)

Anais do XXII Workshop de Informática na Escola (WIE 2016)

Os dois projetos versam acerca da influência dos meios de comunicação de massa sobre a produção e interpretação de imagens na sala de aula, em seus distintos formatos, tais como: a fotografia, o cinema, as histórias em quadrinhos, publicidade, os recursos computacionais, memes, dentre outros. Logo, verificou-se os anseios e dificuldades da prática docente através do trabalho com o texto imagético e a inserção das imagens com maior abrangência no currículo escolar.

A elaboração deste artigo girou em torno das seguintes questões: de que forma a inserção do texto imagético no currículo escolar pode auxiliar na melhoria da qualidade de ensino da escola pública? Ou ainda, qual o papel das visualidades nos processos formativos, envolvendo o ensino e as aprendizagens numa perspectiva transversal e multidisciplinar?

A partir destes questionamentos, propusemos refletir sobre a narrativa visual como meio de aproximar professor e aluno da cultura e do conhecimento sistemático, capaz de aprimorar o senso crítico, estético e cultural, tanto do aluno quanto da comunidade externa da escola. Estas inquietações possibilitaram uma análise da postura docente e discente, verificando se os mesmos estão ou não verdadeiramente aptos a lidar de forma efetiva, com os meios de comunicação e transformar o meio social no qual estão inseridos, através da utilização das imagens, não apenas como recurso das aulas, mas também como conteúdo destas.

$\mathrm{Na}$ atualidade, os alunos são submetidos a uma superexposição de imagens, veiculadas numa velocidade alucinante pelos meios de comunicação, as quais são vistas de forma natural por eles. Por outro lado, para os professores, reconhecidos como não nativos digitais, tal superexposição representa muitos desafios em face aos avanços tecnológicos que ocorrem de maneira frenética. Tais avanços evidenciam a necessidade que os mesmos têm de adequar os seus fazeres pedagógicos à diversidade presente na sala de aula. Neste contexto, a imagem apresenta-se como uma alternativa de mediação das aprendizagens, pois, o propósito da cultura visual está centrado, segundo Hernández (2007, p. 27), na "relevância que as representações visuais e as práticas culturais têm dado ao 'olhar' em termos das construções de sentido e das subjetividades no mundo contemporâneo". Nesta linha, a lei de Diretrizes e Bases da Educação Nacional - LDB 9394/96 - determina que a escola deve ser democrática e aberta a todos buscando garantir não apenas o acesso, mas também a permanência dos discentes nas escolas. Isto, no cenário atual, apresenta-se como um grande desafio para educação brasileira. Pensando nestas lacunas, implementar novas propostas pedagógicas parece ser um bom começo para uma possível permanência/vivência desses cidadãos.

Assim, a inserção do texto imagético com maior frequência no currículo escolar pode ser considerada socialmente relevante, na medida em que os professores, em uma perspectiva do trabalho com imagens nas mais distintas formas, estariam mais integrados com os discentes em sala de aula, como por exemplo, por meio da realização de oficinas temáticas e intervenções de modo interdisciplinar, com ações que contemplem a apreciação e análise de imagens em movimento e/ou estáticas, como a fotografia, os quadrinhos, o cinema, mídias tecnológicas, dentre outros. Desse modo, as imagens passam a ser inseridas não apenas como recurso para as aulas, mas como conteúdo, transformando-se em conhecimento e favorecendo assim, o aprimoramento do potencial crítico-reflexivo dos discentes, bem como a melhoria das habilidades de leitura e escrita, ainda tão incipientes. 
Portanto, o trabalho com os filmes/cinema, bem como com as imagens construídas e veiculadas nas redes socais visa incentivar uma práxis em que a docência não se restrinja ao cumprimento das tarefas rotineiras, podendo ir muito além do tradicional, na busca pela inovação e motivação dos alunos. Tais propostas atribuem ao aparato visual, uma importância em termos de inovação, do ponto de vista didático e uma dimensão política ligada aos valores humanos que podem ser abordados e refletidos de maneira transversal, em diversas disciplinas do currículo escolar.

A seção 2 trata sobre questões transversais ao uso pedagógico de imagens; a seção 3 discute sobre inovação no âmbito escolar e a importância do PIBID neste contexto; a seção 4, apresenta as intervenções dos projetos PIBID referente ao uso do cinema e imagens no Facebook; e, finalmente, a seção 5, considerações finais.

\section{A Transversalidade das Imagens}

Por questões de socialização e sobrevivência, as visualidades nos acompanham em nossa jornada desde os primórdios, muito embora tenhamos criado, em alguns momentos, determinada resistência com a chegada das tecnologias oferecidas pela contemporaneidade. Ao tratarmos do ensino, observamos que a escola, na maioria das vezes, entende que os materiais oriundos dos meios de comunicação servem unicamente para deixar a sala de aula menos entediante. Alguns professores utilizam-na com função meramente ilustrativa, como acontece com o uso da imagem, principalmente nos livros didáticos. Vale ressaltar, que a utilização destas imagens apenas como suporte para a interpretação de textos escritos, torna a sua importância secundária frente aos textos verbais, podendo singularizar o potencial crítico e criativo do aluno.

Sobre tal pensamento, Sardelich (2006, p. 459) esclarece que "é nesse sentido que se considera a produção de imagens como um desses mecanismos educativos presentes nas instâncias socioculturais. As imagens não cumprem apenas a função de informar ou ilustrar, mas também de educar e produzir conhecimento". Estas por sua vez, ganharam força e estão por toda parte, como afirma Sontag (2004, p. 13), "existem à nossa volta muito mais imagens que solicitam nossa atenção". A compreensão crítica da cultura visual permite a articulação entre educação e cultura, conforme argumenta Candau (2008):

\footnotetext{
Parto da afirmação de que não há educação que não esteja imersa nos processos culturais do contexto em que se situa. Neste sentido, não é possível conceber uma experiência pedagógica 'desculturizada', isto é, desvinculada totalmente das questões culturais da sociedade. Existe uma relação intrínseca entre educação e cultura (s). Estes universos estão profundamente entrelaçados e não podem ser analisados a não ser a partir de sua íntima articulação [p. 13].
}

O escopo da cultura visual está centralizado, na visão de Hernández (2007, p. 27), na "relevância que as representações visuais e as práticas culturais têm dado ao 'olhar' em termos das construções de sentido e das subjetividades no mundo contemporâneo". Desse modo, afirma-se que um dos elementos fundamentais para lidar com a cultura visual é a criticidade, pois o olhar individualizado, que desvia-se ao conforto e a permanência das rotinas visuais, é o que ponderamos como 'olhar crítico'. Ele nos orienta ampliar uma visão crítica do mundo e da realidade.

\section{Inovações no Currículo Escolar}


V Congresso Brasileiro de Informática na Educação (CBIE 2016)

Anais do XXII Workshop de Informática na Escola (WIE 2016)

Ao tratarmos da contemporaneidade, afirmamos que a escola vem passando por diversas mudanças, sendo elas, ideológicas, políticas e conceituais. As instituições de ensino, na maioria das vezes conhecedoras de tais mudanças, têm voltado o olhar a repensar suas práticas pedagógicas e, consequentemente, planejar espaços que propiciem aos discentes, às aprendizagens coerentes com este novo cenário mundial. Nessa linha, Alves et al (2015) afirmam que o mundo pós-moderno aponta a velocidade das inovações tecnológicas, visto que estas certamente influenciam a própria língua. Tais transformações no ensino escolar, possibilitam aos alunos assumirem uma nova postura que os distanciem do ensino tradicional, com uma busca frenética de interações na contemporaneidade por intermédio de novas tecnologias (MANSUR, 2011; MARCON et al, 2012). Deste modo, para assegurar uma maior motivação entre alunos e professor, faz-se necessário redimensionar as ações escolares, atentos às demandas contemporâneas da sociedade da informação.

Sendo assim, afirma-se que o PIBID, inserido no âmbito da escola, constituiu-se como peça valiosa, tanto para auxiliar o docente nas atividades desenvolvidas em sala de aula, como em toda unidade escolar. Observou-se que houve progressos nas unidades escolares onde foram desenvolvidas as ações dos subprojetos que contemplavam a compreensão crítica da cultura visual. A atuação do PIBID na escola e a aceitação dos alunos frente às mudanças assumidas pela unidade escolar, proporcionam um itinerário voltado à exploração das possibilidades múltiplas das imagens oriundas dos meios de comunicação, ou mesmo oferece transformações curriculares importantes através de possíveis modificações da prática pedagógica. A respeito da utilização das imagens na escola, percebe-se que, segundo Hernández (2007),

[...] as imagens são mediadoras de valores culturais e contém metáforas nascidas da necessidade social de construir significados. Reconhecer essas metáforas e seu valor em diferentes culturas, assim como estabelecer as possibilidades de produzir outras, é uma das finalidades da educação para a compreensão da cultura visual [p.133].

Observa-se que o autor defende a ideia de que a sociedade desempenha uma constante elaboração de sentidos múltiplos, os quais emergem das imagens que produz. Logo, a educação para a imagem é tarefa crucial na formação do aluno da educação básica. Igualmente, é preciso a efetivação de metodologias condizentes com o estudo e produção do imagético; ou mesmo, práticas enraizadas que não surtem mais efeitos, devem abrir espaço para novas ideias.

De outro modo, partindo do princípio de que o PIBID também atua com bolsistas que são professores em formação, estes adentram o universo escolar com ideias e propostas, fomentando o desejo de tornar a escola um ambiente mais estimulante e prazeroso para toda a comunidade escolar. $\mathrm{O}$ trabalho realizado entre educandos, bolsistas do PIBID, professores e demais segmentos da escola, podem favorecer à aprendizagem, inclusive ampliar o nível de familiaridade com as tecnologias e demais ferramentas digitais como bem assegura Gomes (2008),

(...)Precisamos de professores inquietos, andarilhos, eternos aprendizes, que sejam capazes de largar a mesa e a cadeira de professor e aprender em meio aos conglomerados e nas mais inusitadas situações. Que busquem analisar a as novas configurações sociais, podendo, então, se diferenciar, significar e significar sua permanência em sociedade. O professor desse novo tempo tem que ser acima de tudo aprendiz. Aprendiz no sentido investigativo que o termo 
V Congresso Brasileiro de Informática na Educação (CBIE 2016)

Anais do XXII Workshop de Informática na Escola (WIE 2016)

comporta. (...) O professor não pode temer a evolução tecnológica porque ela é inevitável. Deve ser um aprendiz dela. [p. 19].

Paralelo a isso, outro aspecto a ser considerado como fator relevante e decisivo nos resultados obtidos pela escola, refere-se à organização curricular. Estas por sua vez, necessitam adequar seus currículos às demandas dos alunos, ao mundo do trabalho, à tecnologia da informação, dentre outros paradigmas essenciais do mundo atual.

Nessa vertente percebe-se que determinadas ações podem ser altamente benéficas para alavancar as práticas docentes no âmbito escolar e aprimorar habilidades básicas dos educandos que, infelizmente, na realidade da escola pública, nem sempre são alcançadas e, tais lacunas os acompanham até o ensino médio. Essas práticas também podem ser sistematizadas e tornarem-se objeto de pesquisa do professor que verificará os resultados obtidos, bem como, irá propor alternativas para modificar o trabalho pedagógico, a fim de que o perfil docente deste contexto contemporâneo esteja vinculado às novas demandas sociais, principalmente no que se refere à utilização do acervo imagético produzido pelos meios de comunicação de massa.

Faz-se necessário envolver os educandos com os gêneros textuais oriundos da sociedade pós-moderna, que por sua vez, são entrelaçados à informação que os circundam no dia-a-dia. A autonomia do aluno diante da interpretação de textos, sobretudo os imagéticos, privilegia o desenvolvimento do olhar crítico do educando que vive em intenso contato com as imagens, na sua capacidade de interpretar e as compreender criticamente. As práticas de atividades de leitura, escrita e produção de textos lineares e imagéticos, somados a um olhar crítico e minucioso, capaz de absorver informações diversas, oriundas das mais distintas imagens que são veiculadas diariamente através dos meios de comunicação de massa, permitem que o aluno atribua sentidos múltiplos às imagens analisadas, tornando-se capazes de aprimorar o raciocínio crítico diante do contexto social que o circunda.

\section{A Intervenção do Pibid com os Projetos "Cinema Na Escola" e (Re)Visando Imagens no Facebook}

No ambiente educacional, os meios de comunicação de massa vêm assumindo uma importante função de apoio pedagógico, como recurso mediador de uma aprendizagem dinâmica. Porém, entendemos que este recurso não substitui a figura do professor, ele assume o papel de auxiliar no processo de ensino e aprendizagem. Se faz necessário que o professor acompanhe os avanços nos meios de comunicação, a exemplo das ferramentas digitais oferecidas pela modernidade, de maneira apropriada para o bom desempenho e eficácia de seu trabalho escolar.

Entre as ações desenvolvidas pelo subprojeto do PIBID intitulado "Cultura Visual e Aprendizagens: Leitura e Práticas Transversais", ganha destaque o "Cinema na escola", que teve como propósito a promoção do lazer educativo e a aproximação da comunidade com a escola. O projeto teve como objetivo, oportunizar aos alunos, pais e comunidade externa, o acesso aos bens culturais e formativos oferecidos pelo cinema. Em relação a forma de ensino tradicionalmente adotada nas escolas, o projeto visa ainda promover práticas inovadoras, ao atribuir uma maior importância ao aparato visual, além de proporcionar ao mesmo uma dimensão política ligada aos valores humanos que podem ser abordados e refletidos de maneira transversal, em diversas disciplinas do currículo escolar. 
V Congresso Brasileiro de Informática na Educação (CBIE 2016)

Anais do XXII Workshop de Informática na Escola (WIE 2016)

Propostas como estas estão espalhas nas mais variadas áreas de ensino, todas na tentativa de promover o contato entre diferentes manifestações artísticas e culturais, para assim, contribuir com a formação cultural de um povo. A exemplo, temos relatos de experiência de Pereira e Franco, da Universidade Federal de Uberlândia (UFU), que apresentaram um trabalho com alunos da educação básica, entre o período de 2012 à 2014. Teve como objetivo trazer os alunos à universidade para assistirem a projeções fílmicas em estrutura de cinema, configurando uma ferramenta de aprendizagem por meio de atividade recreativa, estimulante e lúdica. Percebeu-se com a aplicação desde trabalho, uma receptividade por parte das escolas, tendo em vista que o cinema estabeleceu-se como ferramenta pedagógica de grande relevância para esses alunos, pois interagiram de maneira dinâmica. Pode-se perceber que com o acesso ao cinema e ao ambiente universitário, foi possível complementar a educação em um ambiente não formal.

No entanto, acredita-se que atividades desta natureza apresentem melhores resultados dentro da própria escola, pois além de possibilitar o acesso da comunidade ao ambiente escolar, promove aos aluno um outro olhar diante do âmbito educacional, aquele visto apenas como um espaço destinado ao cumprimento de ordens estabelecidas pelos professores.

Por ter sido desenvolvido em uma região interiorana de uma escola da rede pública, logo nos deparamos com algumas limitações para a execução do projeto "Cinema na Escola", tais como: espaço físico, indisponibilidade dos alunos e comunidade, dentre outros. Mesmo com estes percalços, foi possível perceber que estamos diante de uma viável possibilidade de melhoria na qualidade da educação, pois o cinema nos permite essa possibilidade de identificar e conhecer novas representações sociais, culturais e raciais, ao entrarmos em contato com filmografias nacionais e internacionais, sem mencionar o lazer educativo que estes propõem.

Foi observado a partir da fala da comunidade externa que se fez presente no "Cinema na Escola", a importância daqueles momentos proporcionados no ambiente escolar, tendo em vista que muitos nunca frequentaram um cinema, apenas assistem pela televisão, filmes ou programas que são disponibilizados pelas emissoras. Ainda assim, muitos relataram não terem o hábito de assistir filmes. Apresentando uma síntese sobre o cinema, é válido ressaltar que nem sempre ele esteve presente em nossas vidas, como nos dias atuais. Ainda é relevante apontar, que mesmo no século XXI, esta prática de ir ao cinema não é realidade de todos. Isso acontece por diversos motivos: carência de recursos financeiros, não ter cinema na cidade, falta de interesse, dentre outros. Diante dessa realidade, Duarte (2002) afirma que,

(...) ir ao cinema, gostar de determinadas cinematografias, desenvolve os recursos necessários para apreciar os mais diferentes tipos de filmes, etc., longe de ser apenas uma escolha de caráter exclusivamente pessoal, constitui uma prática social importante que atua na formação geral das pessoas e contribui para distingui-las socialmente. [p. 14].

Desse modo, afirmamos que o filme permite ao indivíduo demonstrar sua expressão de liberdade. Através dele, um mundo pode aparecer diante dos seus olhos, sem sair do lugar. Novas reflexões e questionamentos irão surgir em cada indivíduo. Criase condições para que haja reflexão crítica, pois através das imagens, ele criará sua própria história e seu próprio modo de ver e interpretar o mundo. Daí, a eficácia do uso de filmes, 
V Congresso Brasileiro de Informática na Educação (CBIE 2016)

Anais do XXII Workshop de Informática na Escola (WIE 2016)

tanto como uma ferramenta pedagógica, como para a formação do ser. Para tal pensamento, Oliveira (2005) propõe que,

As transposições e as vivências que a linguagem cinematográfica possibilitam são tão marcantes, que muitas vezes elas se tornam as referências profundas e comuns pelas quais a ciência e a tecnologia são percebidas por grande parte da sociedade. Mais do que aprendizagens derivadas das práticas educativas formais, as experiências vivenciadas nos filmes acabam compondo boa parte do arsenal simbólico no qual a opinião pública vislumbra o alcance dos empreendimentos científicos e tecnológicos. [p.8]

A partir desta análise preliminar, percebe-se que o cinema, se utilizado como recurso pedagógico multidisciplinar, favorece o processo de ensino - aprendizagem, de modo multidisciplinar, e em qualquer modalidade de ensino. Os filmes escolhidos para serem exibidos no projeto "Cinema na Escola", eram de responsabilidade dos bolsistas do PIBID e definidos em reuniões mensais. Este momento era destinado à sugestões de filmes verificando de que maneira eles poderiam ser relevantes para os alunos e comunidade. Todos os filmes exibidos buscaram contemplar os temas transversais, pertinentes às várias disciplinas do currículo escolar. As exposições aconteciam uma vez a cada mês. A regra aplicada aos alunos era levar como acompanhante, um membro da família ou um amigo. Isso, no intuito de aproximar a comunidade externa para o ambiente escolar. Interessante relatar que, mesmo este público, em sua maioria, não tendo o hábito de assistir filmes, tão pouco ir ao cinema, faziam questão de a cada filme, se expressarem acerca do momento vivenciado.

Atrair o público às escolas, não tem sido uma tarefa fácil. Esta realidade é vivenciada nos ambientes escolares a cada dia, onde percebe-se um número ainda considerável de evasão nas escolas. Sendo assim, um trabalho que possa promover ensino e lazer, pode ajudar a sanar tais problemas. Contudo, cabe à escola, como espaço educacional público que tem o papel de fornecer ensino coletivo integrado à capacidades metodológicas, sugerir um trabalho que envolva "educação cinematográfica". Dessa forma, ela poderá proporcionar, tanto à comunidade como à escola, novas formas de leitura de mundo e de valores morais, que por sua vez, são abordagens promovidas pelo mundo cinematográfico.

$\mathrm{Na}$ oficina intitulada “(Re)visando as imagens nas rede sociais”, ação desenvolvida a partir do subprojeto do PIBID "Educação pela imagem: Formação cultural, leitura e escrita", o qual se refere ao trabalho com os artefatos visuais construídos e disseminados nas redes sociais, vale apontar alguns conceitos previamente: de acordo com Lemos (2010), a Cibercultura, também compreendida como Cultura Digital, trata-se de uma forma sociocultural que transforma hábitos sociais, práticas de consumo cultural, velocidade na produção e distribuição da informação, responsável pela gênese de novas relações no trabalho, lazer, novas formas de sociabilidade e de comunicação social, a partir do aprimoramento e utilização constante das Tecnologias de Informação e Comunicação Digitais (TDICs). Dentre estas, os smartphones (celular, no senso comum) dizem respeito à conjugação de mídias distintas, as quais podem ser grandes artífices de artefatos visuais.

Alguns trabalhos foram desenvolvidos a partir de experiências leitoras efetivadas através de redes sociais e tecnologias digitais. Neves (2014) desenvolve seu trabalho em torno da revolução digital e o impacto desta sobre a literatura, na busca de compreender sobre as formas como os textos são construídos em ambientes virtuais e como a sociedade 
V Congresso Brasileiro de Informática na Educação (CBIE 2016)

Anais do XXII Workshop de Informática na Escola (WIE 2016)

lhes atribui valor. Rojo (2013) centra a sua discussão acerca das práticas de leitura e escrita desenvolvidas no ciberespaço, provocando a escola a repensar suas práticas de leitura e escrita frente às novas demandas da contemporaneidade que se constitui por sujeitos cada vez mais submersos nas tecnologias digitais, circunstância que os mantém cada vez mais em contato com artefatos da cultura visual.

É notória a sedução que as TDICs exercem sobre as pessoas de modo geral, em especial sobre os educandos e, para estes, será muito mais instigante buscar informações, apreciar imagens, hipertextos, comunicar-se com o mundo através dos aparatos tecnológicos, de maneira a tornarem-se colecionadores "de informações" nas salas de aula. Estas, por sua vez, seguem uma dinâmica educativa descontextualizada com as novas demandas da contemporaneidade. Orofino (2005, p. 29), afirma que "a escola pode e deve intensificar o diálogo entre a cultura escolar e a cultura midiática, ao oferecer oportunidades de produção de narrativas de autoria dos estudantes com o uso de novas linguagens e tecnologias".

Compartilhando de ponto de vista semelhante, graças às transformações alucinantes em relação à cultura digital, Santaella (2013) aponta um tipo de leitor diferenciado, sobretudo no âmbito escolar, o que ela chama de leitor ubíquo. Uma das razões que contribuíram para o aparecimento desses novos leitores são os equipamentos de telefonia celular, os smartphones, tendo em vista a sua capacidade de possibilitar que o usuário se mantenha sempre conectado e em constante contato com os aparatos visuais. As visualidades presentes nas tecnologias fornecem subsídios para análise de processos sociais, visto que apresentam conflitos, estereótipos, situações e contextos a serem discutidos pelos sujeitos escolares, os quais nem sempre têm habilidades que lhes permitam notar conexões montadas e articuladas às tecnologias para atingir determinados objetivos. Além disso, possibilitam o exercício de práticas discursivas distintas daquelas usualmente estabelecidas em ambientes educativos.

Diante dessa discussão, nota-se que o professor precisa estabelecer um paralelo entre a sua prática pedagógica e o contexto contemporâneo marcado pela fortíssima influência das imagens veiculadas, sobretudo pelas TDICs, as quais têm propiciado o surgimento de novos paradigmas no universo escolar. Nessa vertente, algumas mídias que aparentemente podem representar uma grande ameaça ao trabalho docente, em contrapartida, assinalam a oportunidade de tornar significativo o processo de construção de sentidos nas aprendizagens de leitura. Assim, frente a necessidade de verificar a capacidade crítico-interpretativa do educando frente às imagens do ciberespaço é que foi desenvolvido um trabalho para reflexão sobre as imagens disseminadas no Facebook, com a Oficina $(\mathrm{Re})$ visando imagens nas redes sociais. Este trabalho objetivou trazer para as aulas, estímulos visuais comumente encontrados nas redes sociais dos nossos discentes.

O trabalho com as imagens nas redes sociais foi de grande relevância, pois através dele vivenciamos a proposta do subprojeto do PIBID na escola. Tratou-se ainda da formação cultural, já que os textos publicados pelos alunos são reflexos da cultura dos mesmos. Evidenciamos ainda, a leitura através da discussão sobre estímulos visuais, onde trabalhamos a reflexão acerca da produção escrita colocada em comentários e status do ciberespaço. Esta experiência revelou que os educandos do ensino médio têm uma concepção muito ingênua acerca das imagens que veiculam nas redes sociais, curtindo e compartilhando artefatos os quais muitas vezes eles próprios não analisam os impactos 
V Congresso Brasileiro de Informática na Educação (CBIE 2016)

Anais do XXII Workshop de Informática na Escola (WIE 2016)

elou as possibilidades de sentidos das suas criações e publicações. Entretanto, após as intervenções em salas de aula, percebeu-se um maior cuidado e olhar crítico em relação ao que se produz e publica nas redes sociais, perceptível nos comentários feitos em atividades propostas nesses ambientes virtuais e posteriormente nas suas páginas de interação.

\section{Considerações finais}

Considerando as transformações da sociedade pós-moderna em virtude da evolução das Tecnologias da Comunicação e Informação, é de grande relevância a inserção de práticas educativas que envolvam a cultura visual nos currículos escolares da educação básica, tendo em vista que imagens, códigos, símbolos e diversas representações visuais constroem nossas experiências e identidades socialmente. Além disso, desenvolver um trabalho incluindo a linguagem fílmica, propicia à comunidade, dentro e fora do ambiente escolar, novas formas de sentido para formação cultural e educacional. Também, propicia aos docentes, inovações no domínio tecnológico e conhecimento da relação que existe entre a cultura escolar, as linguagens audiovisuais e a tecnologia digital.

As possibilidades de novas práticas que se apropriem das redes sociais e seus artefatos visuais se consolidam através da realização de oficinas temáticas e intervenções em sala de aula, de modo interdisciplinar, cujas ações contemplam a apreciação e análise de imagens que circulam nas redes sociais, visando o fortalecimento de outras práticas escolares. Tais fazeres são capazes de favorecer a construção de aprendizagens, o desenvolvimento de competências cognitivas que auxiliem nas práticas de leitura, no refinamento da criticidade do educando que o faz produzir sentidos múltiplos diante das imagens e o consequente aprimoramento da relação aluno/escola/TDICs, posturas que foram verificadas posteriormente nas novas postagens, nos comentários feitos em atividades propostas nesses ambientes virtuais, nas discussões em sala de aula e nas suas páginas de interação.

Para tanto, pode-se observar que a proposta da inserção do trabalho pedagógico com as imagens, bem como a linguagem fílmica, não se limita a algumas disciplinas do currículo escolar. É evidente que estas podem ser inseridas no planejamento dos professores das mais diversas áreas do ensino. Podem ainda, serem implementadas através da elaboração de projetos multidisciplinares ou pequenas intervenções que valorizem a imagem como não apenas um recurso didático para que o aluno aprenda determinado conteúdo, mas como o próprio conteúdo.

Em síntese, vale enfatizar que a perspectiva da utilização pedagógica da cultura visual é socialmente relevante, na medida em que a escola está inserida num contexto social pós-moderno, no qual o avanço tecnológico, jamais visto na escola, demanda práticas de ensino que contemplem o universo "digital" do qual a imagem faz parte.

\section{Referências}

ALVES, Thelma Panerai; SILVA, Ivana Maria Martins; de Carvalho, Ana Beatriz Gomes. Linguagens, tecnologias e educação: interconexões pedagógicas. Recife: Editora UFPE. 2015. 
V Congresso Brasileiro de Informática na Educação (CBIE 2016)

Anais do XXII Workshop de Informática na Escola (WIE 2016)

CANDAU, V. M. Multiculturalismo e educação: desafios para a prática pedagógica". In: Moreira, A. F; Candau, V. M.(Org.) Multiculturalismo: Diferenças Culturais e Práticas Pedagógicas. $2^{\mathrm{a}}$ ed. Petrópolis, RJ: Vozes. Cap. 1, p. 13-37. 2008.

DUARTE, Rosália. Cinema e Educação. Belo Horizonte: Autêntica. 2002.

GOMES, Antenor Rita; SILVA, Núbia Oliveira da. O imagético, a multimodalidade e os hipertextos: novas interfaces da comunicação no facebook. Hipertextus Revista Digital. 2014.

GOMES, Antenor Rita; SILVA, Núbia Oliveira da. Imagem E Conhecimento: Sentidos Moventes, Emergências E Aprendizagem Reu, Sorocaba, SP, v. 39, n. 2, p. 451-461, dez. 2013.

HERNÁNDEZ, Fernando. Catadores da Cultura Visual - proposta para uma nova narrativa educacional. Porto Alegre: Mediação. 2007.

LEMOS, André. (2010) Cibercultura: tecnologia e vida social na cultura contemporânea. $5^{\mathrm{a}}$ ed. Porto Alegre: Sulina.

MANSUR, Andre F. Uebe; CARVALHO, Rogerio A de; BIAZUS, Maria Cristina Mansur V. Rede de Saberes Coletivos (ReSa): um Ambiente Complexo para Aprendizagem Acadêmica por meio de Redes Sociais. In: Anais do Workshop de Informática na Escola 2011, p. 1284-1293. 2011.

MARCON, Karina; Machado, Juliana Brandão; Carvalho, Marie Jane Soares. (2012) Arquiteturas Pedagógicas e Redes Sociais: Uma experiência no Facebook. In: Anais do Simpósio Brasileiro de Informática na Educação.

NEVES, André de Jesus. Cibercultura e Literatura Identidade e Autoria em Produções Culturais Participatórias e na Literatura de Fã (Fanfiction). Jundiaí: Paco editorial, 2014.

OLIVEIRA, B. J. (org.) História da Ciência no Cinema. UFMG, Belo Horizonte, Editora Argumentum. 2005.

OROFINO, Maria Isabel. Mídias e mediação escolar: pedagogia dos meios, participação e visibilidade. São Paulo: Cortez.2005.

PEREIRA, Ana Rúbia Muniz dos Santos; FRANCO, Minéia Cristina. Em Extensão. Uberlândia, v. 14, n. 2, p. 143-154, jul./dez. 2015.

SANTAELlA, L. Desafios da ubiquidade. Revista Ensino Superior Unicamp, Campinas: Unicamp, v. 9, p. 19-28, abr./jun. 2013.

SARDELICH, Maria Emilia. Leitura de imagens, cultura visual e prática educativa. Cadernos de Pesquisa, volume 36, número 128, páginas 451-472. 2006.

ROJO, Roxane (org). Escola conectada: os multiletramentos e a TICs. São Paulo: Parábola, 2015.

SONTAG, Susan. Sobre fotografia. São Paulo: Companhia das Letras, 2004. 